\title{
Criteria for Approximating Certain Microgravity Flow Boiling Characteristics in Earth Gravity
}

\author{
HERMAN MERTE, JR., JAESEOK PARK, WILLIAM W. SHULTZ, \\ AND ROBERT B. KELLER
}

University of Michigan, Ann Arbor, Michigan, USA

\begin{abstract}
The forces governing flow boiling, aside from system pressure, are buoyancy, liquid momentum, interfacial surface tensions, and liquid viscosity. Guidance for approximating certain aspects of the flow boiling process in microgravity can be obtained in Earth gravity research by the imposition of a liquid velocity parallel to a flat heater surface in the inverted position, horizontal, or nearly horizontal, by having buoyancy hold the heated liquid and vapor formed close to the heater surface. Bounds on the velocities of interest are obtained from several dimensionless numbers: a two-phase Richardson number, a two-phase Weber number, and a Bond number. For the fluid used in the experimental work here, liquid velocities in the range $U=5-10 \mathrm{~cm} / \mathrm{sec}$ are judged to be critical for changes in behavior of the flow boiling process. Experimental results are presented for flow boiling heat transfer, concentrating on orientations that provide the largest reductions in buoyancy parallel to the heater surface, varying \pm 5 degrees from facing horizontal downward. Results are presented for velocity, orientation, and subcooling effects on nucleation, dryout, and heat transfer. Two different heater surfaces were used: a thin gold film on a polished quartz substrate, acting as a heater and resistance thermometer, and a gold-plated copper heater. Both transient and steady measurements of surface heat flux and superheat were made with the quartz heater; only steady measurements were possible with the copper heater. R-113 was the fluid used; the velocity varied over the interval $4-16 \mathrm{~cm} / \mathrm{sec}$; bulk liquid subcooling varied over $2-20^{\circ} \mathrm{C}$; heat flux varied over $4-8 \mathrm{~W} / \mathrm{cm}^{2}$.
\end{abstract}

KEYWORDS: flow boiling; microgravity; Earth gravity

NOMENCLATURE:

Bo

$C_{b}$

$C_{s}$

F

$g, g_{e}$

Nd

$R$

$R e$

$R i_{2 \varphi}$

$T$

$U$

$U$
$W e_{2 \varphi}$

Earth gravity acceleration component parallel to heater surface

Bond number, Equation (8)

buoyancy coefficient

surface tension coefficient

force

gravity and Earth gravity acceleration

dimensionless number, Equation (6)

bubble radius

Reynolds number

two-phase Richardson number, Equation (5)

temperature

velocity

two-phase Weber number, Equation (7)

Address for correspondence: Herman Merte, Jr., Mechanical Engineering Dept., 2026 G.G. Brown Building, University of Michigan, Ann Arbor, MI 48109-2125, USA. Voice: 734-7645240; fax: 734-647-3170.

merte@umich.edu

Ann. N.Y. Acad. Sci. 974: 481-503 (2002). (C2002 New York Academy of Sciences. 


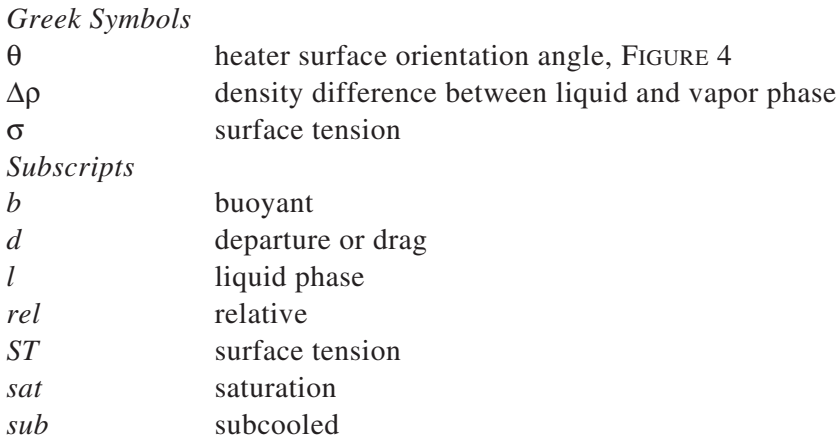

\section{INTRODUCTION}

The elements constituting the flow boiling process can be delineated as follows:

1. Nucleation-or the onset of boiling. These are not necessarily identical. The latter occurs once in a transient heat up, whereas nucleation may take place repetitively at a given location.

2. Vapor bubble growth and collapse. These may occur at the nucleation site or as the bubble is transported downstream by the bulk liquid.

3. Structure of the two-phase flow-for example, bubbly, slug, annular, and the corresponding pressure drop.

4. The local heater surface heat flux associated with the two-phase flow structures and with the various types of liquid-vapor phase changes possible-for example, nucleate boiling, film boiling (or dryout-CHF), and droplet-liquid film evaporation. This is to be expressed in terms of the existing significant local parameters, including heater surface temperature, void fraction, fluid properties, and heater surface geometry and microgeometry.

It is readily obvious, as is well documented by Hewitt ${ }^{1}$ and others, that the phenomenon under consideration is quite complex: The advancement of its truly fundamental understanding requires considerable simplification in experimentation before synthesis of its description can take place. The present work hopefully contributes in this direction.

The opportunity to study flow boiling in the absence of buoyancy is intrinsically important, not only because of the potential space applications, but for Earth bound applications as well. The removal of gravity simplifies the boiling process in that certain features, otherwise disturbed by buoyancy, can now be disclosed or examined. However, the elevated cost of long-term space flights, which provide the high quality stable microgravity environment necessary, dictate that the maximum prior use be made of ground testing, including approximations to microgravity behavior. Observations of pool boiling in long-term space flights ${ }^{2,3}$ with relatively large flat heater surfaces indicate that the growing vapor bubbles tend to remain in the vicinity of the heater surfaces. The imposition of a liquid velocity parallel to such a flat heater surface in the inverted position, horizontal or nearly horizontal relative to Earth gravity, might then somewhat approximate certain aspects of the corresponding flow boiling 
process in microgravity in that buoyancy now holds the heated liquid and vapor formed close to the heater surface.

The use of a flat heater surface simplifies the relationships between the bulk liquid flow velocity, heater surface orientation, and vapor motion. The process is further simplified in the work here in that only the onset of flow boiling is considered with initially zero void fraction, and only a pure single component fluid is used whose properties are well defined and not close to the thermodynamic critical state.

It is understood that for a sufficiently large liquid velocity the presence or absence of buoyancy becomes irrelevant: estimates of upper and lower velocity (when buoyancy is irrelevant) and lower velocity (when velocity is negligible) limits for nucleate flow boiling with buoyancy were presented by Kirk and Merte ${ }^{4}$ and for the flow boiling critical heat flux with and without buoyancy by Brusstar et al. ${ }^{5}$ Certain aspects of these are presented below.

\section{BASIS FOR APPROXIMATING MICROGRAVITY IN EARTH GRAVITY}

Flow boiling behavior is governed by the dynamic behavior of the vapor generated, which itself is a consequence of the forces acting at the interface. These can be more precisely expressed in terms of local stresses. For present purposes, however, only the global nature of the forces will be considered, consisting of:

1. Buoyancy arising from a body force acting on the liquid surrounding the vapor bubble.

2. Momentum associated with the externally imposed liquid flow around the vapor bubble and acting parallel to the flow.

3. Interfacial (surface) tensions, considered here as liquid-vapor and liquidsolid-vapor. The former primarily controls the liquid-vapor surface geometry, whereas the latter controls the adhesion or departure of the vapor bubble from the solid heater surface.

4. Viscous shear arising principally from the liquid viscosity.

5. Lift arising from the externally imposed liquid flow around the vapor bubble and acting normal to the flow.

6. Internal vapor pressure generated by the mean liquid-vapor interface temperature provides the driving force for vapor bubble growth and collapse dynamics.

For the purpose of assessing the degree to which flow boiling in Earth gravity may approximate that in microgravity, advantage will be taken of ratios of certain of the above forces, in particular, those associated with the removal of the vapor bubble from its nucleation site at the heater in the inverted horizontal or nearly horizontal position relative to Earth gravity. Since the bulk liquid flow is parallel to the heater surface, only those components of the forces parallel to the heater are considered, including buoyancy.

The normal component of buoyancy as a vapor bubble removal mechanism is modified by inversion of the heater. However, the influence of lift, which is also normal to the heater surface, must be given consideration, and would be of special significance in microgravity. For spherical particles moving in an inviscid fluid parallel to a plane wall, Li et al. ${ }^{6}$ demonstrate that the lift moves the sphere toward the wall. With a viscous fluid, on the other hand, the resulting velocity gradient in duct flow 
causes the sphere to migrate away from the stationary wall. ${ }^{7}$ With Earth gravity buoyancy acting to move the vapor bubble toward the wall for the case considered here, calculations by Ervin ${ }^{8}$ for parameters approximating those present show that such lift can be neglected relative to the buoyancy. In addition, the internal vapor pressure giving rise to the bubble dynamics is neglected for present purposes. This leaves the forces related to buoyancy, momentum (or inertial drag), surface tension, and viscous shear.

Several dimensionless numbers, defined in terms of ratios of these forces acting on the vapor bubbles, are now examined to estimate the conditions under which certain aspects of the flow boiling process in microgravity might be approximated in Earth gravity. These are:

$$
\begin{gathered}
\text { Richardson number } \equiv \frac{\text { buoyancy }}{\text { inertial drag }} \equiv(\text { Froude number })^{-2} . \\
\text { Weber number } \equiv \frac{\text { inertial drag }}{\text { surface tension }} . \\
\text { Bond number } \equiv \frac{\text { buoyancy }}{\text { surface tension }} . \\
\text { capillary number } \equiv \frac{\text { viscous drag }}{\text { surface tension }} .
\end{gathered}
$$

The capillary number can be expressed as the ratio of the Weber number to the Reynolds number: if the viscous drag in the capillary number were to be replaced by the inertial drag, which would correspond to a Reynolds number of unity, the capillary number would become equivalent to the Weber number. As was demonstrated by the computations of Ervin, ${ }^{8}$ the capillary number affects the lift force acting on a bubble in determining its deformation due to the shear flow. Since lift is being neglected, the capillary number is given no further consideration here.

An expression for a two-phase Richardson number was developed by Kirk and Merte, ${ }^{9}$ in which the buoyant and drag forces acting on a vapor bubble are defined in terms of the bubble radius, the relative velocity between the bubble and the bulk liquid, $U_{\text {rel }}$, and coefficients, $C_{b}$ and $C_{d}$, given by

$$
\begin{gathered}
F_{b}=C_{b} \frac{4}{3} \pi R^{3} g_{e} \Delta \rho, \\
F_{d}=C_{d} \pi R^{2} \rho_{l} \times \frac{U_{r e l}^{2}}{2} .
\end{gathered}
$$

The buoyancy coefficient, $C_{b}$, accounts for the difference between a spherical bubble of radius, $R$, and that of a non-spherical bubble of equal mean radius, and $C d$ is the drag coefficient, determined empirically. The drag force can be considered to be a manifestation of the net bulk flow momentum effects acting on the vapor bubble. The characteristic bubble radius, $R$, in Equations (1) and (2) is taken to be the departure bubble radius $R_{d}$. Once the vapor bubble has departed its local nucleation site it can be considered to no longer directly influence the local heat transfer processes. An expression for the departure radius was obtained from a force balance on a vapor bubble growing from its nucleation site, using Equations (1) and (2), together with a surface tension force, $F_{s}$, at the solid-liquid-vapor contact line, 


$$
F_{s}=C_{s} \sigma R \text {. }
$$

The surface tension coefficient, $C_{s}$, was obtained empirically from the balance of buoyancy and surface tension forces for the case of pool boiling by equating (3) and (1), with $C_{b}=1$. Using the measured departure radius $0.50 \mathrm{~mm}$ for R-113, the surface tension coefficient was found to be approximately unity.

An estimate of the drag coefficient, $C_{d}$, was determined empirically from a balance of the buoyant and drag forces, Equations (1) and (2), parallel to a heating surface at which an immediately adjacent spherical bubble was moving. Measurements of the bubble rise velocities, sizes, and liquid velocities were made for various orientations $\theta$ of the flat heating surface relative to the horizontal face-up position (see FIG. 4), such that $g_{e}$ in (1) is replaced by

$$
g=g_{e} \sin \theta .
$$

Over a range of bubble Reynolds numbers from 24 to 920 the drag coefficient, $C_{d}$, is roughly constant and equal to 0.56 . This compares well with the turbulent drag coefficient of 0.50 for a solid sphere. Further details are available from Kirk and Merte. $^{4}$

Taking the ratio of (1) and (2) as the two-phase Richardson number, together with the coefficients given above,

$$
R i_{2 \varphi}=\frac{1}{2}\left(\sqrt{1+21.7 N_{d}}-1\right)
$$

where

$$
N_{d}=\frac{g \Delta \rho \sigma}{\rho_{l}^{2} U^{4}} .
$$

The liquid velocity $U$ is taken as $U_{r e l}$ in (2), and $g$ is given by (4).

Equation (5) is plotted in FIGURE 1 for R-113 at atmospheric pressure, for three orientation angles, and the range of velocities used here.

A two-phase Weber number is obtained by taking the ratio of (2) to (3), resulting in

$$
W e_{2 \varphi}=\frac{0.1}{N_{d}}\left(\sqrt{1+21.7 N_{d}}-1\right)=0.2 x \frac{R i_{2 \varphi}}{N_{d}} .
$$

Equation (7) is shown in FIgURE 2 for the similar conditions as those in FIGURE 1.

In a similar manner the Bond number is obtained by taking the ratio of (1) to (3), and can be represented as

$$
B o=0.42\left(21.7-4 \frac{R i_{2 \varphi}}{N_{d}}\right),
$$

or, equivalently, as

$$
B o=9.1\left(1-W e_{2 \varphi}\right) \text {. }
$$

Equation (8) is plotted in FIGURE 3 for similar conditions as those in FIGURES 1 and 2.

For $\theta=180^{\circ}$, where buoyancy is acting normal to the flat heater surface, these three dimensionless number take on singular values, given by 


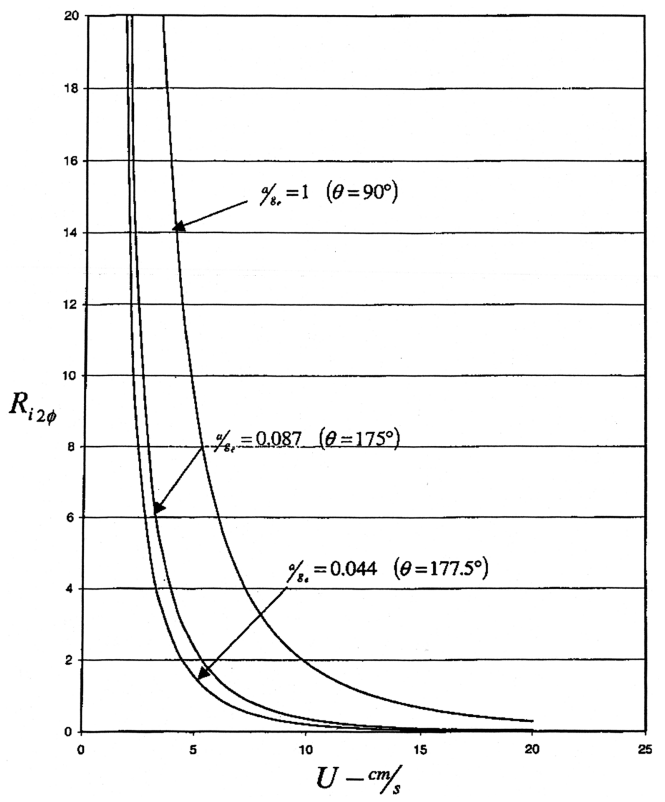

FIGURE 1. Two-phase Richardson number for R-113 at $P=1$ atmosphere.

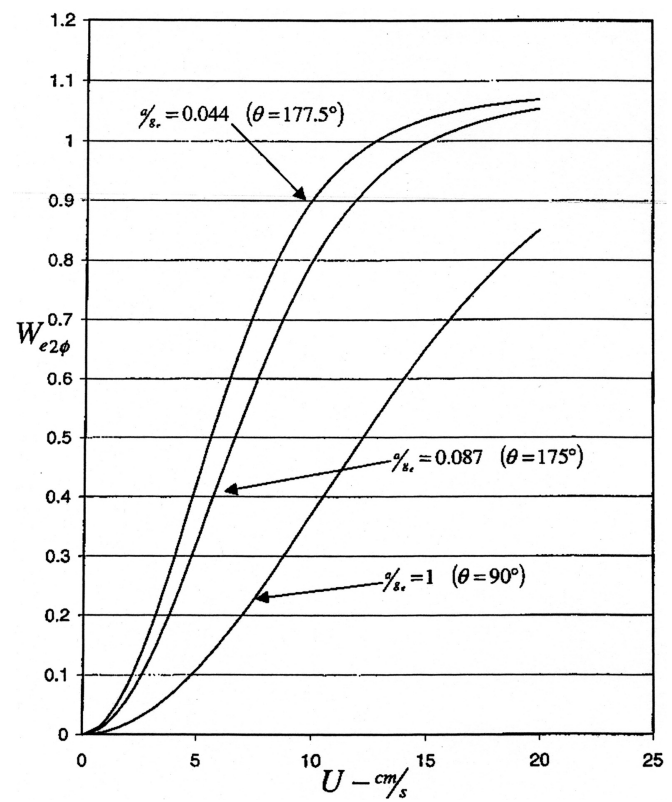

FIGURE 2. Two-phase Weber number for R-113 at $P=1$ atmosphere. 


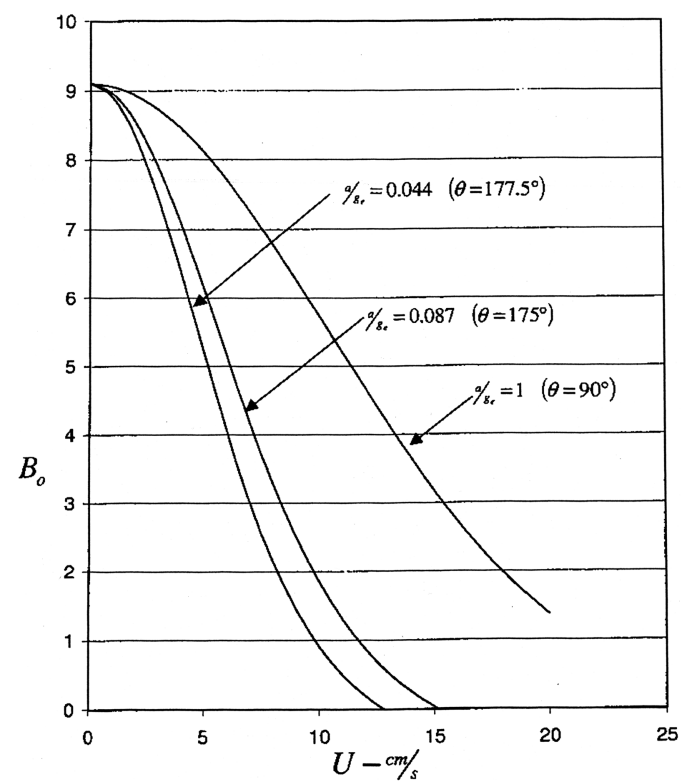

FIGURE 3. Bond number for R-113 at $P=1$ atmosphere.

$$
\left.\begin{array}{rl}
R i_{2 \varphi} & \rightarrow 0 \\
W e_{2 \varphi} & \rightarrow 1 \\
B o & \rightarrow 0
\end{array}\right\}
$$

Of course, the assumptions under which the vapor bubble departure sizes are computed are no longer valid here.

Making use of FIGURES $1-3$, the conditions for possibly simulating microgravity flow boiling, or certain elements of it, in Earth gravity are now examined:

Two-Phase Richardson Number. FIGURE 1

$$
R i_{2 \varphi}=\frac{F_{\text {buoy }}}{F_{\text {drag }}} \text {, desire small } R i_{2 \varphi} \text {, but low } U .
$$

$$
\text { At } \theta=175^{\circ} \text { and } 177.5^{\circ} \text { with } U \approx 5-10 \mathrm{~cm} / \mathrm{sec} ; R i_{2 \varphi}<2 \text {. }
$$

Two-phase Weber Number. FIGURE 2

$$
W e_{2 \varphi}=\frac{F_{d r a g}}{F_{S T}} \text {, desire small } W e_{2 \varphi}, U<5 \mathrm{~cm} / \mathrm{sec} .
$$

At $\theta=175^{\circ}$ and $177.5^{\circ}$ with $U \approx 5-10 \mathrm{~cm} / \mathrm{sec} ; W e_{2 \varphi} \approx 0.3-0.9$.

Bond Number. FIGURE 3

$$
\begin{gathered}
B o_{2 \varphi}=\frac{F_{\text {buoy }}}{F_{S T}} \text {, desire small } B o, \text { but not too low } U . \\
\text { At } \theta=175^{\circ} \text { and } 177.5^{\circ} \text { with } U \approx 5-10 \mathrm{~cm} / \mathrm{sec} ; B o_{2 \varphi} \approx 1-6 .
\end{gathered}
$$


It appears that liquid velocities in the range of $U=5-10 \mathrm{~cm} / \mathrm{sec}$ might be judged as critical or illuminating for changes in behavior of the flow boiling process. The next phase is to examine the behavior of the various facets of flow boiling over this range of liquid velocities with orientations in the vicinity of horizontal facing downward.

\section{DESCRIPTION OF EXPERIMENTAL HARDWARE}

A schematic of the forced convection boiling loop is given in FIGURE 4. The loop is mounted on an axis near its center of gravity such that it can be rotated a full 360 degrees while in operation in order to obtain the various heater surface orientations. The loop consists of five basic components: the test section, the condenser-cooler, the flow system, the pressure control system, and the preheater system. Degassed R-113 was employed as the test fluid. The sufficiency of the degassing process was demonstrated by comparing the measured vapor pressure curve with published saturation properties over the domain of interest.

The test section provides a rectangular flow cross section $10.80 \mathrm{~cm}$ wide by $1.27 \mathrm{~cm}$. high by $35.56 \mathrm{~cm}$ long $(4.25 \times 0.50 \times 14.0 \mathrm{in})$, capable of accommodating three heater surfaces on each side. Viewing windows made from optical grade quartz permit a transverse view of the boiling process on the flat heaters. The condensercooler system condenses R-113 vapor leaving the test section, and subcools the

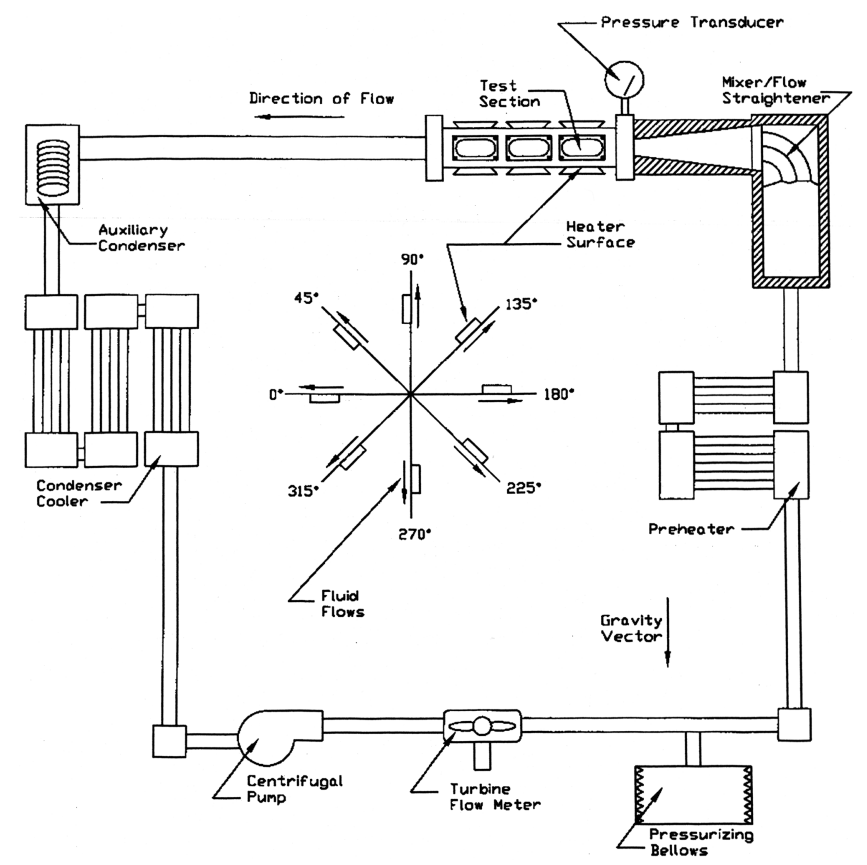

FIGURE 4. Forced convection flow loop. 
liquid sufficiently to avoid cavitation at the pump inlet. The pressure control system actively maintains the pressure in the flow loop to within $\pm 0.34 \mathrm{kPa}(0.05 \mathrm{psi})$, and consists of four main components: a bellows, valves, electronic control circuits, and a pressure transducer. The $17.78 \mathrm{~cm}$ (7.0in) diameter stainless steel bellows separates the test fluid from the air in the chamber surrounding the bellows. Air is continuously admitted to the chamber through a manually adjusted needle valve, and is vented from the chamber through an electronically controlled proportional valve. The preheater is used to raise the temperature of the R-113 to the desired level at the inlet to the test section.

The heater surfaces installed in the test section were of dimensions larger than the bubbles growing on them in order that they be more representative of boiling surfaces encountered in engineering applications. Two types of relatively large test surfaces, with dimensions $1.905 \times 3.81 \mathrm{~cm}(0.75 \times 1.50 \mathrm{in}$.), were employed in this study: a thin gold film heater deposited on a quartz substrate, and a gold-coated copper substrate heater, referred to as the "metal" surface.

The semitransparent thin gold film surface functions simultaneously as a heater and as a resistance thermometer, and consists of nominally $400 \AA$ thick gold sputtered on a highly polished quartz substrate, which was presputtered with $20 \AA$ of tantalum for improved gold adhesion. Measurement of the resistance of the thin film heater provides a spatially averaged mean surface temperature, with an uncertainty of $\pm 1.0^{\circ} \mathrm{C}$.

The metal heater consists of a copper block with a film heater on the underside and embedded in an electrical encapsulating potting compound. A smooth copper foil $0.0254 \mathrm{~mm}(0.001 \mathrm{in})$ thick was soldered to the copper block and to the stainless steel holder to eliminate artificial boiling, which otherwise would result at the heater edge. The copper foil was sputtered with gold, approximately $1,000 \AA$ thick, to provide the identical surface-liquid energy combination as for the gold deposited on quartz. A chromel-constantan thermocouple with a bead of $0.64 \mathrm{~mm}(0.025 \mathrm{in})$ diameter was inserted into a $0.76 \mathrm{~mm}(0.030 \mathrm{in})$ diameter hole in the copper heater in order to estimate the temperature of the copper foil. The hole for the thermocouple was then filled with a thermally conducting copper compound. The tip of the thermocouple was about $0.76 \mathrm{~mm}(0.030 \mathrm{in})$ from the gold-sputtered copper foil. The metal heater surface temperature had an error of $\pm 0.1^{\circ} \mathrm{C}$, while that of assuming that the temperature of the thermocouple was equal to the surface temperature was estimated to be less than $0.002^{\circ} \mathrm{C}$.

Because of their different constructions, the thin gold film heater provides a uniform heat flux, with a spatial temperature variation in the flow direction; the metal copper heater provides a uniform surface temperature with a spatial variation in the heat flux in the flow direction. Both transient and steady measurements of heat flux and heater surface superheats were made with the thin film heater; only steady measurements were possible with the metal copper heater. Additional details of the flow loop, heaters, and experimental procedures followed are available elsewhere. ${ }^{4,10}$ 


\section{RESULTS}

The results presented here were obtained with the two flat heater surfaces described above facing horizontally downward $\theta=180^{\circ}$, with variations in the orientation angles within \pm 5 producing very small changes in the buoyancy components parallel to the heat surfaces. The bulk liquid velocity at the inlet to the test section was varied over the range of $4-16 \mathrm{~cm} / \mathrm{sec}$; the bulk liquid subcooling was varied over the range of $2.5-20.2^{\circ} \mathrm{C}$ by changing the system pressure appropriately; the input heat flux was varied over $4-8 \mathrm{w} / \mathrm{cm}^{2}$. A total of 314 experiments were conducted over the range of parameters given above, the complete set of results is included in Merte et al. ${ }^{11}$ However, only selected results are included below that demonstrate the interrelationships between buoyancy parallel to the flow direction, both aiding and in opposition to the flow, and velocity, subcooling, and heat flux. Prior work covering wider ranges of each of the above parameters (except for subcooling) are summarized in the APPENDIX.

The transient heating experiments with the gold film heater on a quartz substrate are presented first, followed by the steady state experiments with the copper substrate heater. The transient heating entails a step input in heater power and naturally reverts to the steady state over a sufficiently long period of time. Some steady results with the thin gold film heater are superimposed on the steady state results with the copper substrate heater for purposes of comparison.

\section{TRANSIENT HEATING WITH THE THIN GOLD FILM ON QUARTZ}

Since the thermal conductivity (and the thermal diffusivity) of the quartz substrate is on the order of 20 times that of the R-113, the initial transient heat flux to the R-113 is less than the steady state level, with the rate of increase in the mean (and local) heater surface temperature depending on the fluid velocity. This becomes obvious from FIGURES 5-7, in which the mean heater surface superheats are plotted as a function of time, all for fixed values of subcooling $\left(11.1^{\circ} \mathrm{C}\right)$ and input heat flux $\left(4 \mathrm{w} / \mathrm{cm}^{2}\right)$, with four successive increases in velocity $(4-16 \mathrm{~cm} / \mathrm{sec})$ for each of the three orientations. In interpreting the behavior observed, it must be kept in mind that for orientation angles $\theta<180^{\circ}$, the component of buoyancy, whether with a heated liquid or with a vapor present, is acting in the same direction as the flow velocity, whereas for $\theta>180^{\circ}$ it is acting counter to the flow velocity. For $\theta=180^{\circ}$ buoyancy acts normal to the flow velocity. Also included in each of FIGURES 5-7, for reference purposes, are the heater surface superheats computed assuming one-dimensional heat conduction for the case of an infinitely large heater with a stagnant liquid. This approximates the transient heating process for pool boiling in microgravity. When corrections were made for three-dimensional conduction effects in the quartz substrate, the computed mean surface temperatures agree quite well with measurements, as reported in Merte et al. ${ }^{2}$ Attention is to be drawn to several items in FIGURES 5-7:

1. As the velocity increases with each orientation, not only does the rate of heater surface temperature rise decrease because of the increase in heat transfer to the liquid, accompanied by an increase in the time required for the onset of boiling, 


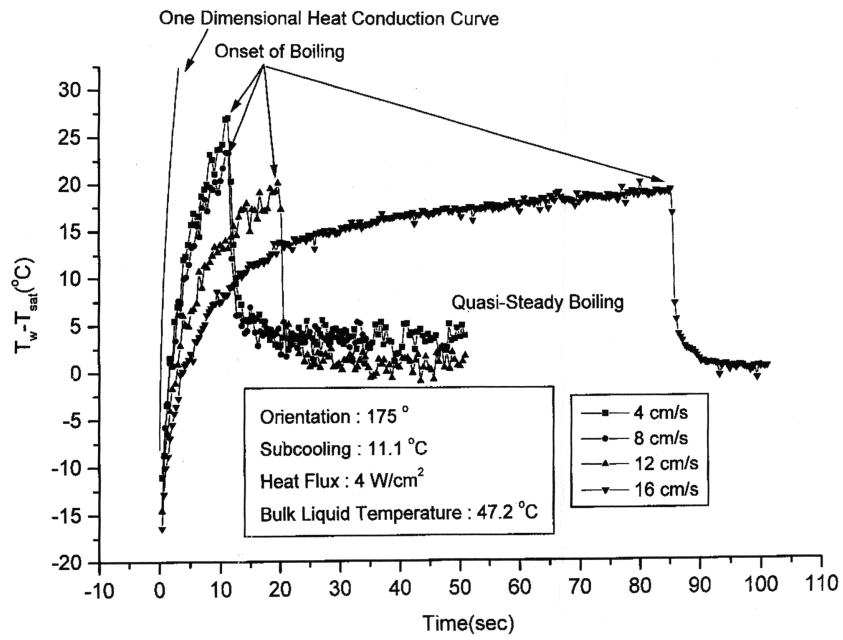

FIGURE 5. Transient flow boiling-quartz substrate. Effect of velocity for $\theta=175^{\circ}$, $\Delta T_{\text {sub }}=11.1^{\circ}, q_{\text {in }}^{\prime \prime}=4 \mathrm{~W} / \mathrm{cm}^{2}$.

as indicated on the figures, but the heater surface superheat at which nucleation takes place is in general reduced. This is interpreted as supporting the concept that the temperature gradient in the liquid in the vicinity of the heater surface has a significant effect on the nucleation process, as discussed in Merte and Lee. ${ }^{12}$

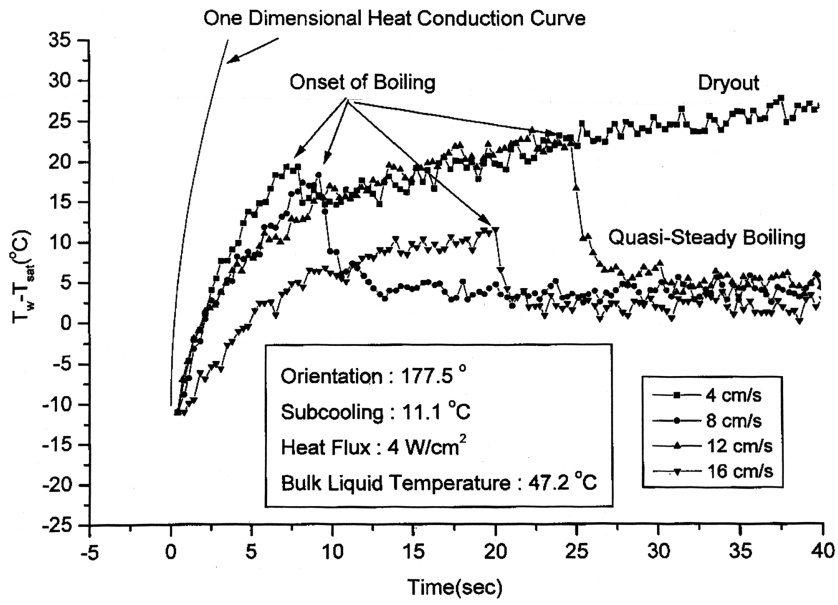

FIGURE 6. Transient flow boiling - quartz substrate. Effect of velocity for $\theta=177.5^{\circ}$, $\Delta T_{\text {sub }}=11.1^{\circ}, q_{\text {in }}^{\prime \prime}=4 \mathrm{~W} / \mathrm{cm}^{2}$. 


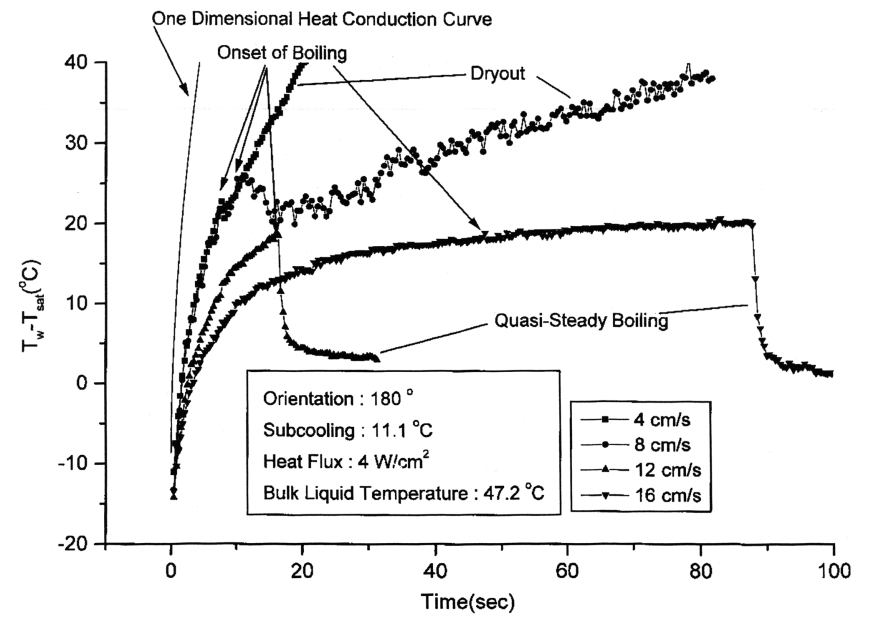

FIGURE 7. Transient flow boiling-quartz substrate. Effect of velocity for $\theta=180^{\circ}$, $\Delta T_{\text {sub }}=11.1^{\circ}, q_{\text {in }}^{\prime \prime}=4 \mathrm{~W} / \mathrm{cm}^{2}$.

2. No dryout (DO) occurs at any velocity in FIGURE 5 for $\theta=175^{\circ}$, where the buoyancy in the flow direction is the strongest. With a reduction in this buoyancy for $\theta=177.5^{\circ}$ in Figure 6 , dryout takes place at the lowest velocity $U=4 \mathrm{~cm} / \mathrm{sec}$. With a further reduction of buoyancy to zero with $\theta=180^{\circ}$ in FIGURE 7 , dryout occurs at the two lower velocities of $U=4$ and $8 \mathrm{~cm} / \mathrm{sec}$. For this same orientation and the velocity of $U=4 \mathrm{~cm} / \mathrm{sec}$, dryout took place at all levels of liquid subcooling used here, up to $\Delta T_{s u b}=20.2^{\circ} \mathrm{C}$. As is observed in FIGURE 8 below, for this same orientation and a velocity of $U=8 \mathrm{~cm} / \mathrm{sec}$, dryout occurs at all but the highest level of liquid subcooling. The data are not shown here, but for this same orientation of $\theta=180^{\circ}$, heat flux $q_{i n}^{\prime \prime}=4 \mathrm{~W} / \mathrm{cm}^{2}$ and the lowest subcooling $\Delta T_{\text {sub }}=2.5^{\circ} \mathrm{C}$, dryout took place following nucleation for all velocities $U=4-16 \mathrm{~cm} / \mathrm{sec}$.

3. For each orientation, the indicated quasisteady boiling processes, so called since the length of time used was not sufficient to assure true steady conditions, become more effective with increasing velocity, as indicated by a decrease in the heater surface superheat. For $U=8 \mathrm{~cm} / \mathrm{sec}$, the quasisteady boiling effectiveness is virtually unchanged between the buoyancy changes in FIGURES 5 and 6, and the same is true for $U=12$ and $16 \mathrm{~cm} / \mathrm{sec}$ between FIGURES $5-7$.

FIGURES 8 and 9 present the transient heater surface superheat for the fixed values of orientation with no buoyancy component in the flow direction $\left(\theta=180^{\circ}\right)$, and input heat flux $\left(4 \mathrm{w} / \mathrm{cm}^{2}\right)$, with four successive increases in subcooling $\left(2.5-20.2^{\circ} \mathrm{C}\right)$ for each of the velocities $U=8$ and $12 \mathrm{~cm} / \mathrm{sec}$.

Several observations can be made about FIGURES 8 and 9:

1. These velocities cross the upper limit of the range $U=5-10 \mathrm{~cm} / \mathrm{sec}$, postulated earlier as critical for changes in behavior of the flow boiling process. 


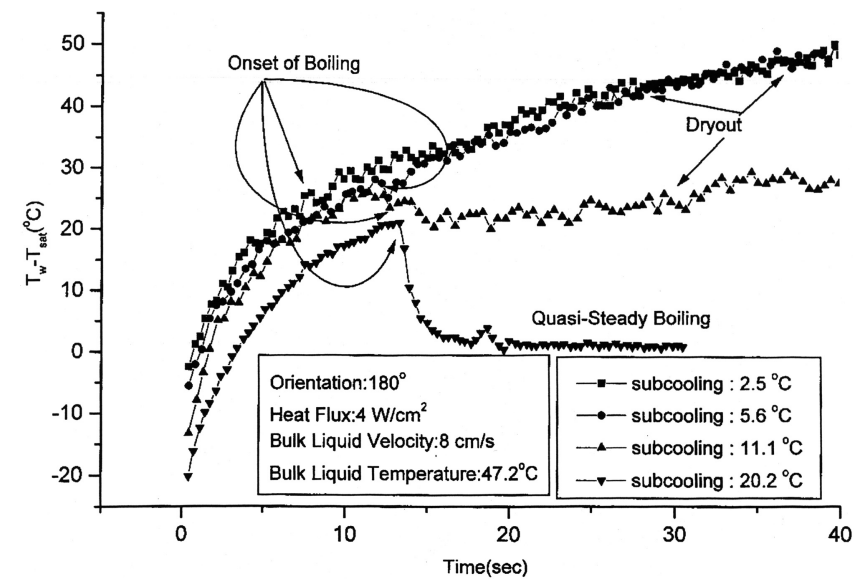

FIGURE 8. Transient flow boiling-quartz substrate. Effect of subcooling for $U=$ $8 \mathrm{~cm} / \mathrm{sec}, \theta=180^{\circ}, q_{\text {in }}^{\prime \prime}=4 \mathrm{~W} / \mathrm{cm}^{2}$.

2. Whereas FIgURE 7 presented the transient flow boiling behavior for $\theta=175^{\circ}$ for various flow velocities, FIGUREs 8 and 9 show the influence of subcooling for the same orientation of $\theta=180^{\circ}$ for $U=8$ and $12 \mathrm{~cm} / \mathrm{sec}$, respectively.

3. At the velocity $U=8 \mathrm{~cm} / \mathrm{sec}$ in FIGURE 8 , except for the two lowest subcoolings, where no change is detected, increasing the subcooling results in modest decreases in the mean heater surface superheat at nucleation. At the higher velocity, $U=12 \mathrm{~cm} / \mathrm{sec}$, in FIGURE 9, no changes again are detected between the two lowest

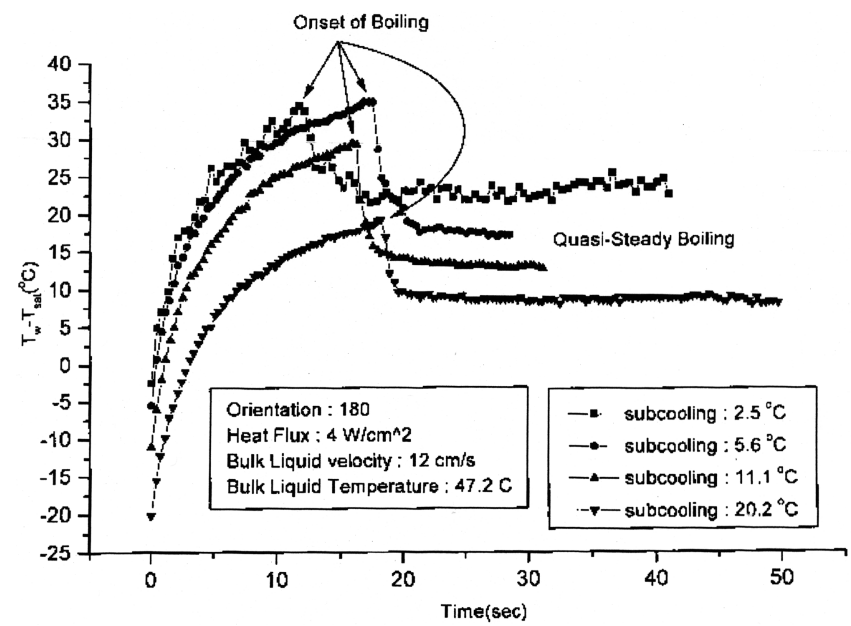

FIGURE 9. Transient flow boiling-quartz substrate. Effect of subcooling for $U=$ $12 \mathrm{~cm} / \mathrm{sec}, \theta=180^{\circ}, q_{i n}^{\prime \prime}=4 \mathrm{~W} / \mathrm{cm}^{2}$. 


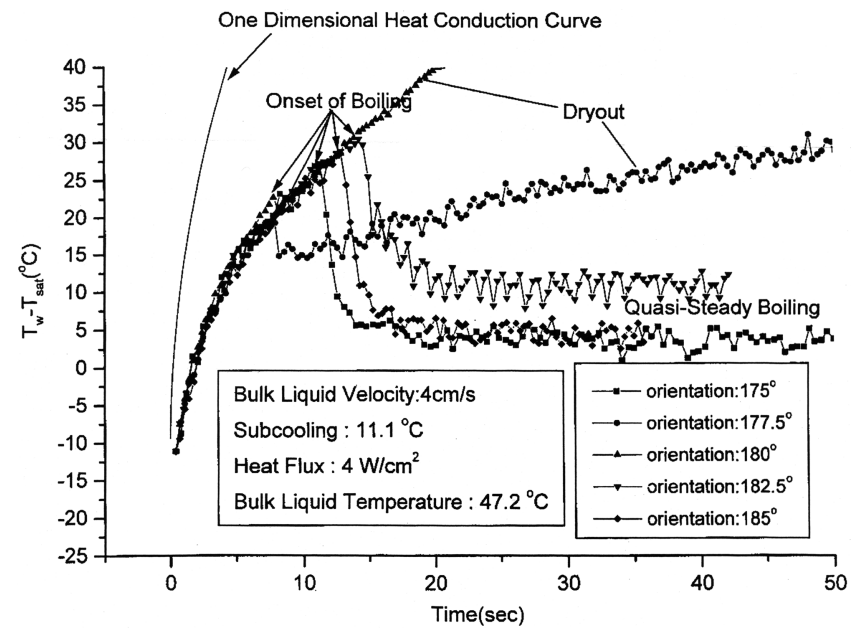

FIGURE 10. Transient flow boiling - quartz substrate. Effect of orientation for $U=$ $4 \mathrm{~cm} / \mathrm{sec}, \Delta T_{\text {sub }}=11.1^{\circ}, q_{\text {in }}^{\prime \prime}=4 \mathrm{~W} / \mathrm{cm}^{2}$.

subcoolings, although the heater surface superheats at nucleation here are about $8^{\circ} \mathrm{C}$ higher than with $U=8 \mathrm{~cm} / \mathrm{sec}$, whereas a dramatic decrease in the heater surface superheat at nucleation occurs at the highest subcooling, indeed decreasing to below that for $U=8 \mathrm{~cm} / \mathrm{sec}$ in FIgURE 8 . This may again be a consequence of the influences that the velocity and subcooling level exert on the liquid temperature gradient adjacent to the heater surface.

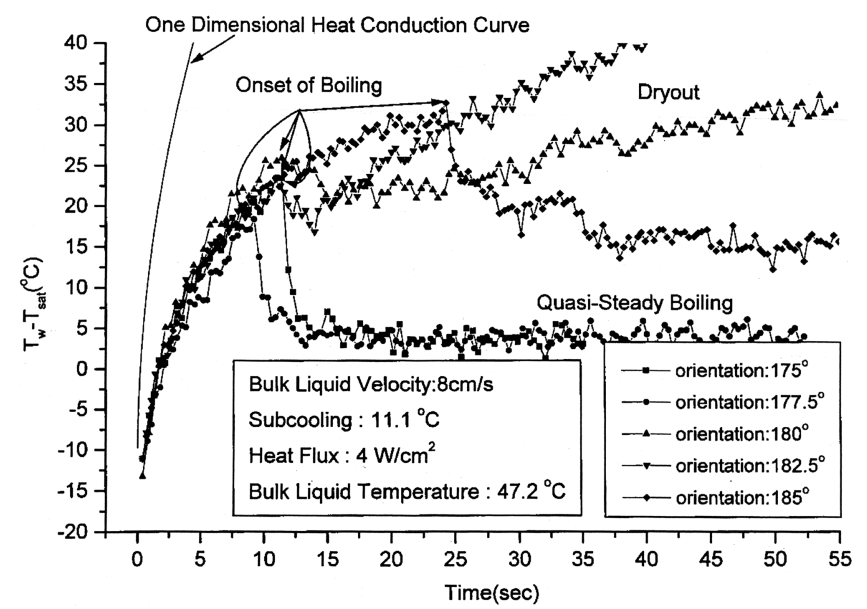

FIGURE 11. Transient flow boiling - quartz substrate. Effect of orientation for $U=$ $8 \mathrm{~cm} / \mathrm{sec}, \Delta T_{\text {sub }}=11.1^{\circ}, q_{\text {in }}^{\prime \prime}=4 \mathrm{~W} / \mathrm{cm}^{2}$. 
4. It is noted that, following the onset of boiling at $U=8 \mathrm{~cm} / \mathrm{sec}$ in FIGURE 8, dryout occurs at all except the highest subcooling, although no dryout takes place when the velocity is increased to $U=12 \mathrm{~cm} / \mathrm{sec}$ in FIGURE 9.

5. For the quasisteady nucleate boiling taking place in both FIGURES 8 and 9, with the highest subcooling of $\Delta T_{\text {sub }}=20.2^{\circ} \mathrm{C}$, the lower velocity of $U=8 \mathrm{~cm} / \mathrm{sec}$ in FIGURE 8 exhibits a considerably more effective heat transfer process, with a mean heater surface superheat of about $1^{\circ} \mathrm{C}$, compared to about $6^{\circ} \mathrm{C}$ in FIGURE 9.

The effects of buoyancy relative to liquid velocity on the transient mean heater surface superheat are illustrated in FIGURES 10-12 for fixed levels of subcooling of $\Delta T_{\text {sub }}=11.1^{\circ} \mathrm{C}$ and input heat flux $q_{i n}^{\prime \prime}=4 \mathrm{~W} / \mathrm{cm}^{2}$. The velocities are increased to $U=4,8,12 \mathrm{~cm} / \mathrm{sec}$ for each of the three figures, respectively, whereas the orientation angles are incremented within each figure from $\theta=175^{\circ}$ to $\theta=185^{\circ}$ in steps of $\Delta \theta=2.5^{\circ}$. Attention is drawn to the following features:

1. As the orientation angles within each of FIGURES 10-12 increase, beginning with $\theta=175^{\circ}$, the buoyancy component acting in the flow direction parallel to the heater surface decreases successively, to zero at $\theta=180^{\circ}$, then increases successively in opposition to the flow direction, ending at $\theta=185^{\circ}$.

2. The heater surface superheats at nucleation are given in TABLE 1 for the experiments in FIGURES 10-12. For each of the orientations except $\theta=177.5^{\circ}$, where relatively small changes are observed, the superheats decrease as the liquid velocity increases, with the most dramatic decreases occurring at $\theta=182.5^{\circ}$ and $\theta=185^{\circ}$ for velocity increase from $U=8 \mathrm{~cm} / \mathrm{sec}$ to $U=12 \mathrm{~cm} / \mathrm{sec}$. This is where the liquid velocity is acting counter to buoyancy, and is believed to reflect the combined effects of velocity and buoyancy on the liquid temperature gradient at the heater surface on nucleation. This is supported by the relatively small changes in super-

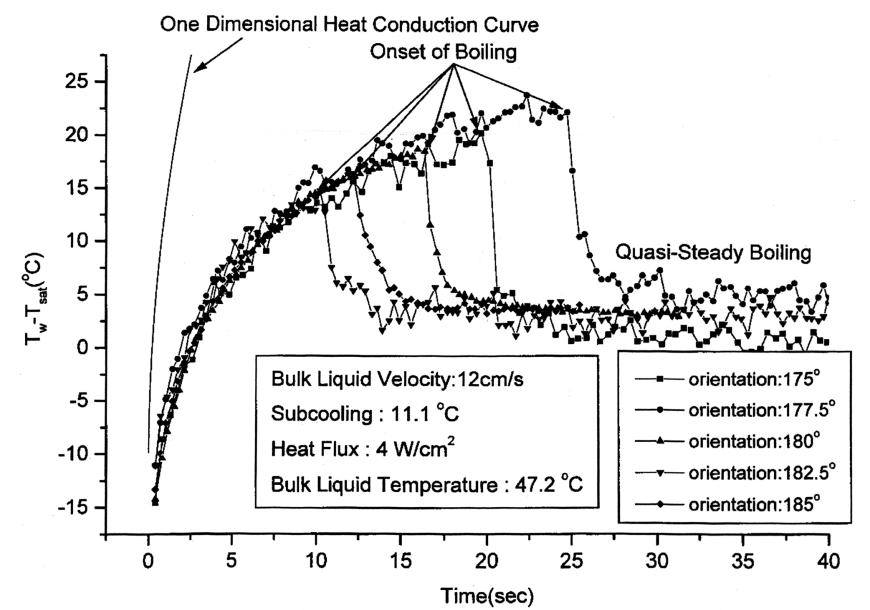

FIGURE 12. Transient flow boiling-quartz substrate. Effect of orientation for $U=$ $12 \mathrm{~cm} / \mathrm{sec}, \Delta T_{\text {sub }}=11.1^{\circ}, q_{\text {in }}^{\prime \prime}=4 \mathrm{~W} / \mathrm{cm}^{2}$. 
TABLE 1. Heater surface superheats at nucleation for Figures 10-12

\begin{tabular}{lccc}
\hline & \multicolumn{3}{c}{ Surface Superheat $\left({ }^{\circ} \mathrm{C}\right)$} \\
\cline { 2 - 4 }$\theta\left({ }^{\circ} \mathrm{C}\right)$ & $U=4 \mathrm{~cm} / \mathrm{sec}$ & $U=8 \mathrm{~cm} / \mathrm{sec}$ & $U=12 \mathrm{~cm} / \mathrm{sec}$ \\
\hline 175 & 26 & 22.5 & 19.5 \\
177.5 & 18 & 18 & 22 \\
180 & 22.5 & 25 & 18 \\
182.5 & 30 & 22.5 & 14 \\
185 & 27.5 & 32.5 & 15.5 \\
\hline
\end{tabular}

heat at $\theta=175^{\circ}$ and $\theta=177.5^{\circ}$, where buoyancy is acting in the flow direction, and changes in flow velocities have less effect on the liquid temperature gradient.

3. For the lowest velocity, $U=4 \mathrm{~cm} / \mathrm{sec}$ in FigurE 10, dryout takes place with $\theta=177.5^{\circ}$ and $\theta=180^{\circ}$. With an increase in velocity to $U=8 \mathrm{~cm} / \mathrm{sec}$ in FIGURE 11 , dryout now takes place with $\theta=180^{\circ}$ and $\theta=182.5^{\circ}$, whereas as the velocity increases further to $U=12 \mathrm{~cm} / \mathrm{sec}$ in FIGURE 12, no dryout takes place.

4. Where quasisteady nucleate boiling is taking place, the large increases in heat transfer effectiveness take place as the velocity is increased to $U=12 \mathrm{~cm} / \mathrm{sec}$ for the orientations of $\theta=182.5^{\circ}$ and $\theta=185^{\circ}$, where buoyancy is acting counter to the flow direction.

\section{STEADY STATE WITH COPPER SUBSTRATE HEATER}

FIGURE 13 shows the typical hysteresis taking place with the copper substrate heater. The established nucleate boiling with increasing and decreasing heat flux are identical. The point from the onset of boiling to the next higher heat flux level have virtually the same input heat flux. The significant increase in heat flux taking place on nucleation is due to the reduction in the calibrated heat loss associated with the reduced heater surface temperature. Calibration of the heat loss is described in detail in Kirk and Merte. ${ }^{4}$ The onset of boiling in FIGURE 13 takes place with a heater surface superheat of $32^{\circ} \mathrm{C}$ and mean heat flux of $1.2 \mathrm{~W} / \mathrm{cm}^{2}$. For the same bulk subcooling and liquid velocity, when the orientation is changed to $\theta=175^{\circ}$, the corresponding levels of superheat and heat flux are $38^{\circ} \mathrm{C}$ and $1.2 \mathrm{~W} / \mathrm{cm}^{2}$. For comparison of the mean heater surface superheat on nucleation with the quartz substrate, FIGURE 9 shows a value of $19^{\circ} \mathrm{C}$, compared with $32^{\circ} \mathrm{C}$ for the identical conditions with the copper substrate.

FIGURES $14-17$ present the steady results with the copper substrate in three orientations, $\theta=175^{\circ}, 180^{\circ}$, and $185^{\circ}$, within each figure, with successively increasing levels of the liquid velocity $U=4,8,12$, and $16 \mathrm{~cm} / \mathrm{sec}$, all for a moderate liquid subcooling level of $\Delta T_{s u b}=5.6^{\circ} \mathrm{C}$. Also superimposed on FigurEs 14-17, for comparison purposes are the quasisteady results with the quartz substrate heater surface, for the same operating parameters of subcooling, velocity, and orientations. It is noted that the steady nucleate boiling results for the two surfaces are not too dissimilar at 


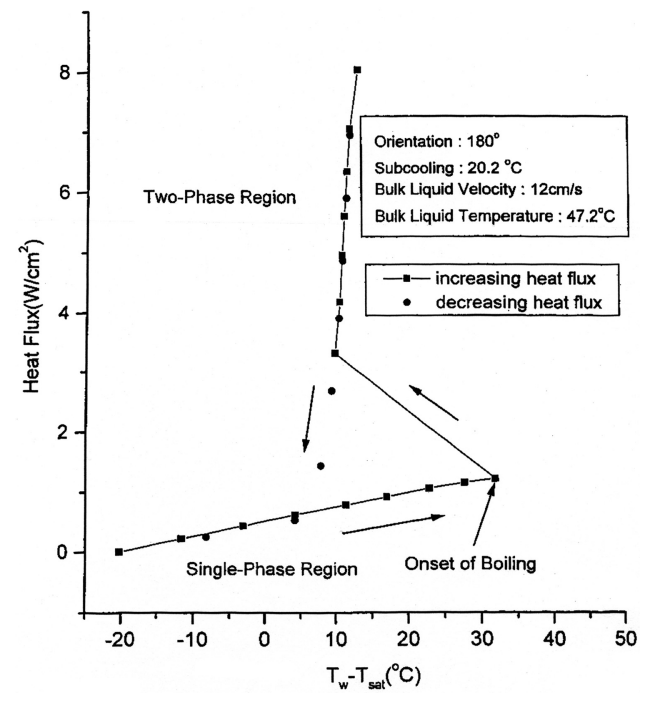

FIGURE 13. Steady flow boiling - copper substrate. Demonstration of hysteresis for $\theta=180^{\circ}, U=12 \mathrm{~cm} / \mathrm{sec}, \Delta T_{\text {sub }}=20.2^{\circ}$.

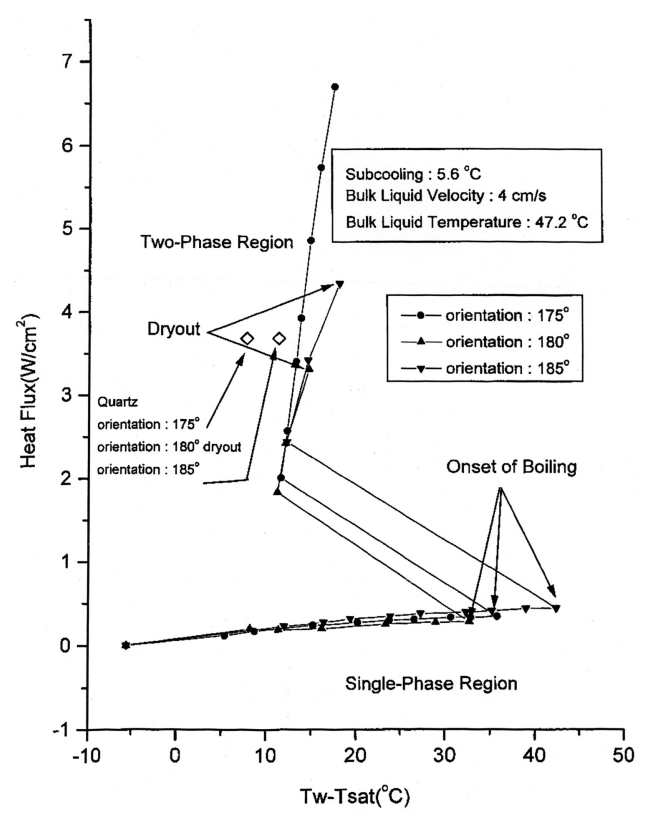

FIGURE 14. Steady flow boiling-copper substrate. Effects of orientation for $U=$ $4 \mathrm{~cm} / \mathrm{sec}, \Delta T_{\text {sub }}=5.6^{\circ}$. 


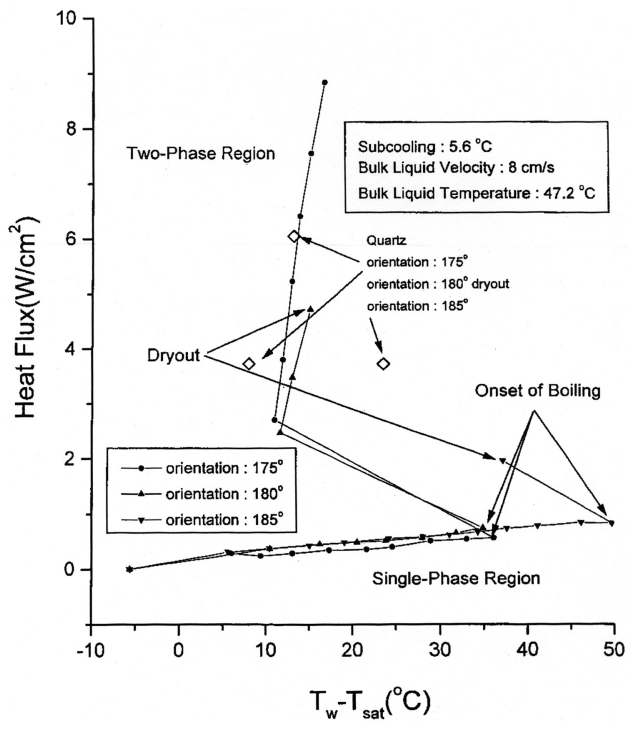

FIGURE 15. Steady flow boiling-copper substrate. Effects of orientation for $U=$ $8 \mathrm{~cm} / \mathrm{sec}, \Delta T_{\text {sub }}=5.6^{\circ}$.

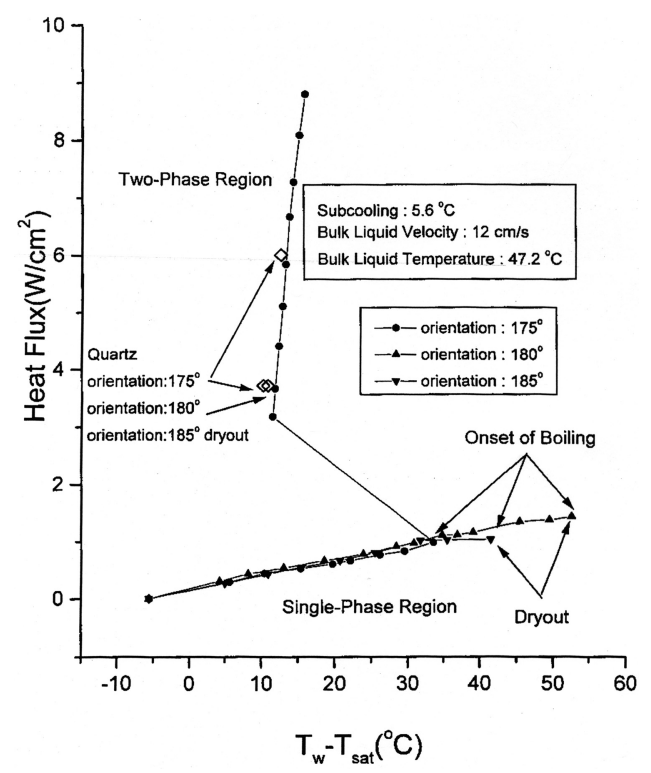

FIGURE 16. Steady flow boiling - copper substrate. Effects of orientation for $U=$ $12 \mathrm{~cm} / \mathrm{sec}, \Delta T_{\text {sub }}=5.6^{\circ}$. 


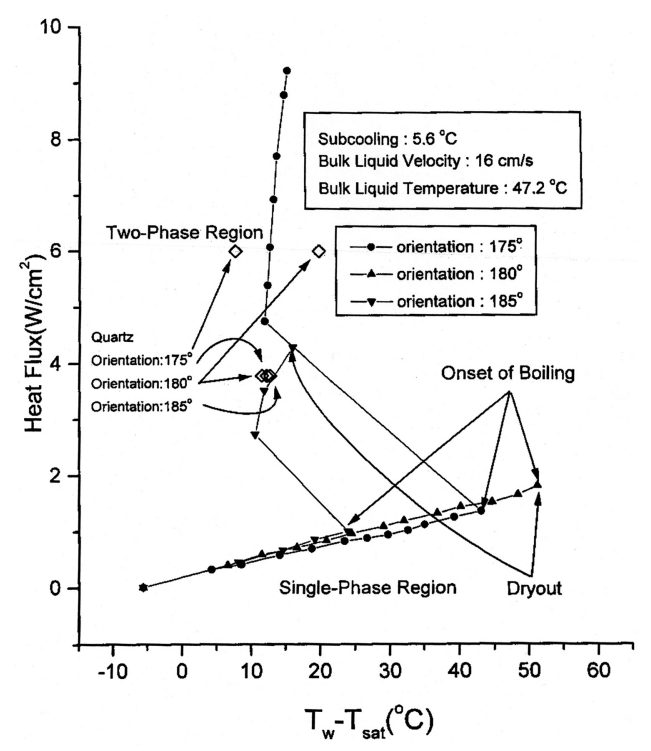

FIGURE 17. Steady flow boiling-copper substrate. Effects of orientation for $U=$ $16 \mathrm{~cm} / \mathrm{sec}, \Delta T_{s u b}=5.6^{\circ}$.

$U=4 \mathrm{~cm} / \mathrm{sec}$ and $U=12 \mathrm{~cm} / \mathrm{sec}$ in Figures 14 and 16, respectively. Dryout takes place at a relatively low heat flux level with the copper substrate heater surface in FIGURE 15, associated with the adverse buoyancy effect, but does not occur with the quartz substrate. In FIGURE 16, with $U=12 \mathrm{~cm} / \mathrm{sec}$, dryout occurs on nucleation with the copper substrate for orientations of $\theta=180^{\circ}$ and $185^{\circ}$, whereas it only takes place at $\theta=180^{\circ}$ with the quartz substrate. The difference is attributed to the larger heater surface superheat existing at nucleation with the copper substrate. As the liquid subcooling is increased to $20.2^{\circ} \mathrm{C}$ with the copper substrate heater for this same velocity, in FIGURE 13, the heater surface superheat at nucleation is reduced to $32^{\circ} \mathrm{C}$, compared with $53^{\circ} \mathrm{C}$ in FIgURE 16, and dryout does not take place. However, dryout on the copper substrate heater occurs even with the larger velocity $U=16 \mathrm{~cm} / \mathrm{sec}$ in FIGURE 17. This has the lower liquid subcooling level of $5.6^{\circ} \mathrm{C}$ compared to $20.2^{\circ} \mathrm{C}$ in FIGURE 13, which contributes to a larger amount of vapor generation.

The steady results for $\theta=180^{\circ}$ with the copper substrate heater in FIGURES $14-17$ are combined in FIGURE 18 to clarify the effects of changing the liquid velocity alone. Increasing the velocity increases the single-phase heat transfer coefficient, as demonstrated by the increasing slope. The two highest velocities result in dryout immediately following nucleation, somewhat contrary to expectations. As stated earlier, the higher superheat at nucleation produces a large amount of vapor, inhibiting the rewetting process. This dryout does not take place with the quartz substrate heater, as can be seen in FIGURE 9, for $U=12 \mathrm{~cm} / \mathrm{sec}$, nor at $U=16 \mathrm{~cm} / \mathrm{sec}$, not included here. The role of liquid subcooling for the copper substrate, which was not shown in FIGURES 14-17, is presented in FIGURE 19 for $\theta=180^{\circ}$ and the velocity 


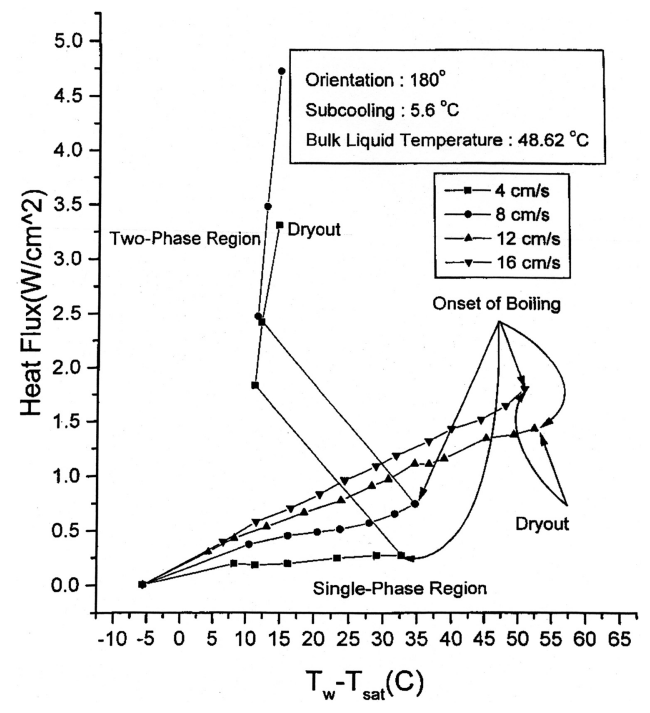

FIGURE 18. Steady flow boiling-copper substrate. Effects of velocity for $\theta=180^{\circ}$, $\Delta T_{\text {sub }}=5.6^{\circ}$.

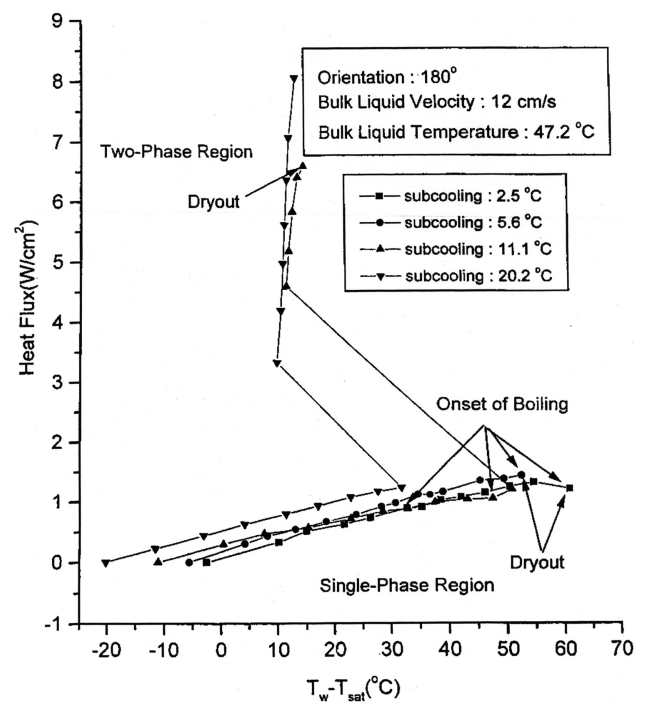

FIGURE 19. Steady flow boiling-copper substrate. Effects of subcooling for, $\theta=180^{\circ}$, $U=12 \mathrm{~cm} / \mathrm{sec}$. 
$U=12 \mathrm{~cm} / \mathrm{sec}$. It is to be noted that dryout now only takes place at the lower two levels of subcooling, $\Delta T_{\text {sub }}=2.5^{\circ} \mathrm{C}$ and $5.6^{\circ} \mathrm{C}$.

\section{CONCLUSIONS}

It has been demonstrated that distinct changes in behavior of nucleation, nucleate boiling, and dryout take place in flow boiling in earth gravity in the inverted orientation, corresponding to simulated microgravity, in velocities between $8-12 \mathrm{~cm} / \mathrm{sec}$ for the fluid used here. This is in the same range determined from the three dimensionless numbers: a two-phase Richarson number, a two-phase Weber number, and a Bond number.

Whether similar behavior occurs in the long-term microgravity of space remains to be demonstrated. However, based on observations with pool boiling in long-term microgravity, it is believed that long-term microgravity flow boiling experiments conceived and carried out with care, covering the full range of parameters expected to be encountered in applications of interest, will generate surprising results. It also becomes clear from the work carried out here that extrapolating transient experiments to steady-state conditions must be carried out with care. Aircraft parabolic flights involve relatively short experimental times, and certain flow boiling behaviors are quite sensitive to the variations of $\pm 0.02 \mathrm{~g}$ inherently present.

\section{ACKNOWLEDGMENTS}

The research presented here was conducted with NASA support under Grant NAG3-1900. The encouragement of Dr. Fran Chiaramonte of the NASA Glenn Research Center is gratefully recognized.

\section{REFERENCES}

1. Hewitt, G.F. 1996. Phenomenological issues in forced convective boiling. In Convective Flow Boiling, John C. Chen, Ed.: 3-14. Taylor and Francis, Washington, D.C.

2. Merte, H. JR., H.S. Lee \& R.B. Keller. 1995. Report on pool boiling experiment flown on STS-47 (PBE-IA), STS-57 (PBE-IB), STS-60 (PBE-IC). NASA Contract NAS 3-25812, Report No. UM-MEAM-95-01. Department of Mechanical Engineering and Applied Mechanics, University of Michigan, Ann Arbor, Michigan. February 1995.

3. Merte, H., JR., H.S. LeE \& R.B. Keller. 1998. Dryout and rewetting in the pool boiling experiment flow on STS-72 (PBE-IIB), STS-77 (PBE-IIA). Final Report, NASA Grant NAG-1684, Report NO. UM-MEAM-98-01. Department of Mechanical Engineering and Applied Mechanics, University of Michigan, Ann Arbor, Michigan. January 1998.

4. KirK, K.M. \& H. Merte, JR. 1992. A study of the relative effects of buoyancy and liquid momentum in forced convection nucleate boiling. Final Report, NASA Grant NAG3-1310, Report No. UM-MEAM-92-06. Department of Mechanical Engineering and Applied Mechanics, University of Michigan, Ann Arbor, Michigan. November 1992. 
5. Brusstar, M.J., H. Merte, JR. \& R.B. Keller. 1995. Relative effects of flow and orientation on the critical heat flux in subcooled forced convection boiling. Final Report, NASA Grant NGT-50928, Report No. UM-MEAM-95-15. Department of Mechanical Engineering and Applied Mechanics, University of Michigan, Ann Arbor, Michigan. July 1995.

6. Li, L., W.W. Schultz \& H. Merte, Jr. 1993. The velocity potential and the interacting force for two spheres moving perpendicularly to the line joining their centers. J. Eng. Math. 27: 147-160.

7. Cherukat, P. \& J.B. McLaughlin. 1993. Wall-induced lift on a sphere. Intl. J. Multiphase Flow 16(5): 899-907.

8. Ervin, E.A. 1993. Computations of Bubbles and Drops in Shear Flow. Ph.D. Thesis, The University of Michigan, Ann Arbor, Michigan.

9. Kirk, K.M. \& H. Merte, JR. 1994. A mixed natural/ forced convection nucleate boiling heat transfer criteria. In Heat Transfer 1994. 7: 479-484.

10. Kirk, K.M., H. Merte, JR. \& R.B. Keller. 1995. Low-velocity subcooled nucleate flow boiling at various orientations. ASME J. Heat Transfer 117: 380-386.

11. Merte, H., JR., J. Park, W.W. Schultz \& R.B. Keller. 2001. Simulation of low velocity subcooled microgravity boiling in earth gravity. Final Report, NASA Grant NAG3-1900, Report No. UM-ME-01-02. Department of Mechanical Engineering, University of Michigan, Ann Arbor, Michigan. April 2001.

12. Merte, H., JR. \& H.S. LeE. 1997. Quasi-homogeneous nucleation in microgravity at low heat flux: experiments and theory. ASME J. Heat Transfer 119: 305-312.

13. Nestel, S.U. \& H. Merte, JR. 1995. The effects of heater surface length in forced convection nucleate boiling. NASA Grant NAG3-1310, Report No. UM-MEAM-95-01. Department of Mechanical Engineering and Applied Mechanics, University of Michigan, Ann Arbor, Michigan. July 1995.

14. Tortora, P.R., H. Merte, Jr., H.S. Lee \& R.B. Keller. 1999. Buoyant and inertial effects in subcooled forced convection nucleate boiling on flat inverted surfaces. NASA Grant NAG3-1900, Report No. UM-MEAM-99-03. Department of Mechanical Engineering and Applied Mechanics, University of Michigan, Ann Arbor, Michigan. April 1999.

15. Liu, Q., H. Merte, Jr., H.S. Lee \& R.B. Keller. 1999. Boiling incipience in subcooled forced convection with a highly-wetting fluid and variable orientation. NASA Grant NAG3-1900, Report No. UM-MEAM-99-09. Department of Mechanical Engineering and Applied Mechanics, University of Michigan, Ann Arbor, Michigan. July, 1999.

\section{APPENDIX}

\section{Prior Flow Boiling Results with Various Orientations}

Kirk and Merte: ${ }^{4}$ nucleate boiling + some dryout.

Heaters: gold film on quartz + copper (slim). Steady.

$q^{\prime \prime}, 0-11 \mathrm{~W} / \mathrm{cm}^{2}$

$\Delta T_{\text {sub }}, 4.4-1.1^{\circ} \mathrm{C}$

$U, 4-32 \mathrm{~cm} / \mathrm{sec}$

$\theta, 0-360^{\circ}, 45^{\circ}$ and $90^{\circ}$ increments.

Brusstar et al..$^{5}$ critical heat flux.

Heaters: copper (heavy) + some gold film. Steady.

$q^{\prime \prime}$, CHF $58.7 \mathrm{~W} / \mathrm{cm}^{2} \max$

$\Delta T_{\text {sub }}, 5.6-22.2^{\circ} \mathrm{C}$

$U, 4-55 \mathrm{~cm} / \mathrm{sec}$

$\theta, 0-360^{\circ}, 15^{\circ}$ and $45^{\circ}$ increments. 
Nestel and Merte: ${ }^{13}$ effect of heater length.

Heaters: gold film on quartz + copper (slim). Steady. $q^{\prime \prime}, 0-10 \mathrm{~W} / \mathrm{cm}^{2}$

$\Delta T_{\text {sub }}, 2.8^{\circ} \mathrm{C}, 5.6^{\circ} \mathrm{C}$, and $11.1^{\circ} \mathrm{C}$

$U, 12,18$, and $32 \mathrm{~cm} / \mathrm{sec}$

$\theta, 0^{\circ}, 90^{\circ}, 135^{\circ}-225^{\circ}$, and $270^{\circ}$.

Tortora et al: $:^{14}$ nucleate boiling, hysteresis.

Heaters: gold film on quartz + copper (heavy). Steady. $q^{\prime \prime}, 0-12 \mathrm{~W} / \mathrm{cm}^{2}$ (quartz). Some CHF 0- $35 \mathrm{~W} / \mathrm{cm}^{2}$ (copper) to $\mathrm{CHF}$

$\Delta T_{\text {sub }}, 5.5^{\circ} \mathrm{C}, 11^{\circ} \mathrm{C}$

$U, 8,18$, and $32 \mathrm{~cm} / \mathrm{sec}$

$\theta, 0,90^{\circ}-270^{\circ}$, in $15^{\circ}$ increments.

Liu et al.: ${ }^{15}$ incipient boiling.

Heaters: gold film on quartz + copper (heavy). Steady. $q^{\prime \prime}, 0-7 \mathrm{~W} / \mathrm{cm}^{2}$ (quartz)

$0-10 \mathrm{~W} / \mathrm{cm}^{2}$ (copper)

$\Delta T_{\text {sub }}, 5-17^{\circ} \mathrm{C}$

$U, 4-28 \mathrm{~cm} / \mathrm{sec}$

$\theta, 0-360^{\circ}, 45^{\circ}$ increments.

Merte et al.: ${ }^{11}$ transient flow boiling near inverted position.

Heaters: gold film (transient + steady) + copper (slim). Steady.

$q^{\prime \prime}, 4,6$, and $8 \mathrm{~W} / \mathrm{cm}^{2}$ (gold film) 0-9W/cm ${ }^{2}$ (copper) some D.O.

$\Delta T_{\text {sub }}, 2.5-20.2^{\circ} \mathrm{C}$

$U, 4,8,12$, and $16 \mathrm{~cm} / \mathrm{sec}$

$\theta, 175^{\circ}, 180^{\circ}$, and $185^{\circ}$. 